\title{
A statistical study on precursory effects of earthquakes observed through the atmospheric vertical electric field in northeast India
}

\author{
Abhijit Choudhury, Anirban Guha ${ }^{\star}$, Barin Kumar De, Rakesh Roy
}

Tripura University, Department of Physics, Suryamaninagar, Agartala, India

\author{
Article history \\ Received October 16, 2012; accepted May 20, 2013. \\ Subject classification: \\ Vertical electric field, Earthquake, Negative bay anomaly, Lithosphere-atmosphere-ionosphere coupling.
}

\section{ABSTRACT}

The study of anomalous variations in the near-surface atmospheric vertical electric field (VEF) that have the form of bay-like depressions in strength have been used as precursors of earthquakes in various studies. We present here the first statistical report from an earthquake-prone zone in northeast India from July 2009 to July 2012. The 10 days that were meteorologically fair and with earthquake occurrences were selected for the present analysis. The average VEF bay durations and depths were ca. 50 min to $70 \mathrm{~min}$, with the corresponding magnitudes of $500 \mathrm{Vm}^{-1}$ to 800 $\mathrm{Vm}^{-1}$. Anomalous variation in VEF before 7 to 12 hour of the impending earthquake has been observed. There was a $31 \%$ probability that a VEF bay would show as an earthquake precursor. The positive correlation coefficient was 0.72 between the VEF bay depth and the ratio of earthquake magnitude to depth, while the negative correlation coefficient of 0.82 was calculated between VEF bay duration and the ratio of earthquake magnitude to depth. There was moderate correlation for distance of the earthquake epicenter to the observation point with both VEF bay depth and VEF bay duration. The correlation of the time difference of VEF variations and earthquakes with VEF bay depth was good, whereas the correlation of the time difference of VEF variations and earthquakes with VEF bay duration was too low to be considered.

\section{Introduction}

The atmospheric vertical electric field (VEF) is generated by thunderstorm discharges that can create a potential difference between the ground and the ionosphere in regions with fair weather [Price 2002, Guha et al. 2010]. The VEF is normally directed downwards and its intensity close to the ground surface is of the order of $100 \mathrm{Vm}^{-1}$ to $200 \mathrm{Vm}^{-1}$ [Bennett and Harrison 2007, Mikhailov et al. 2002]. Electric field measurements at the ground surface have been performed for a long time, to gather cloud charge distributions, and to study the number, intensity and polarity of thunderstorm discharges [Pawar and Kamra 2002]. It is relatively difficult to forecast the severity of thunderstorms due to nonlinearity in the cloud dynamics and the small temporal and spatial extensions [Litta and Mohanty 2008]. However, as the atmospheric VEF is a contributor to the global electric circuit (GEC), it is one of the important parameters for further improvement of the GEC model [Fullekrug 2004]. Moreover, the study of the GEC and atmospheric electricity provide information on the solar-terrestrial weather relationships, as well as on the global temperature and climate change, which link studies of the VEF in fair-weather regions [Bering 1995, Adlerman and Williams 1996, Rycroft et al. 2000].

The fair-weather electricity is defined as the electric field induced by the space charge from an excess of positive ions in the atmosphere, and excluding other phenomena such as local cloud electrification and dust storms [Stow 1969]. During these fair-weather days, there have been several scientific reports of uncharacteristic variations in the atmospheric VEF with respect to fair weather VEF variation prior to earthquakes in various seismo-active regions of the world, as has been shown in reports from countries like Russia, Japan and China [Kondo 1968, Pierce 1976, Rulenko 2000, Hao et al. 2000, Smirnov 2001, Mikhailov et al. 2006, Zhang-Hui et al. 2011]. Interestingly, all of these reports have indicated negative variations in the VEF. These VEF variations usually occur at intervals of a few hours to a few days before an earthquake main shock, and they are seen as either bay-like field intensity decreases or oscillatory trains that last a few hours [Mikhailov et al. 2004]. These anomalous variations are usually classified as short-term earthquake precursors [Pulinets and Ouzounov 2011]. The mechanism of this anomalous electric field generation was described by $\mathrm{Pu}-$ linets and Boyarchuk [2004]. The nature of these effects is possibly related to variations in the stress-strain phenomena in the upper lithosphere that are a result of the preparation of the earthquake source [Mikhailov et al. 2002].

Several possible mechanisms of lithosphere-ionosphere interactions have been suggested in the literature. 
Surface air ionization caused by radon emanation into the atmosphere before earthquakes has also been investigated as one of the major sources of electric field variation [Pulinets et al. 1997, Liperovsky et al. 2008, Harrison et al. 2010]. Moreover, it is evident from the study of Pulinets et al. [1998] that there is a dependence of ionospheric electron density due to seismic variations on local time as well. Studies of low-latitude seismic regions have shown this to be explainable through zonal electric field generation due to equatorial anomalies (Pulinets 2012), hence making the study of VEFs more important from our location, which is at a latitude of $23{ }^{\circ} \mathrm{N}$. Thus, even simply from the enumeration of the sources of the atmospheric electric field variations, it is clear that the problem of separating out earthquake effects is still very complex. In this regard, the present study was designed to provide further insight into forecasting earthquakes with the help of these VEF anomalies.

At the low latitude station of the Department of Physics, Tripura University, India (latitude, $23.75^{\circ} \mathrm{N}$; longitude, $91.25^{\circ} \mathrm{E} ; 42 \mathrm{~m}$ a.s.1.), we have been recording the data from atmospheric VEFs around the clock, from July 2009 to date. This report discusses the preliminary results of the morphological structure of the variations of the VEF with the magnitude of the negative anomaly and with the anomaly duration, and the dependence of these parameters on earthquake magnitude and on the distance between the observation point and the earthquake epicenter. Only negative anomalies were considered; i.e., negative deviations of the VEF from the positive diurnal behavior, in the period from $24 \mathrm{~h}$ before an earthquake occurrence.

\section{Experimental set-up}

To measure the atmospheric VEF, a calibrated Boltek EFM-100 atmospheric electric field monitor (EFM) was installed on the roof of the Department of Physics, Tripura University (India), at $15 \mathrm{~m}$ above ground level. The EFM has six sensor plates, each with dimensions of $17 \mathrm{~cm}$, which are arranged symmetrically around the rotating axis. Six electronically controlled, mechanically grounded, conductive 'choppers' are used to alternately shield and expose the six sensor plates to the atmospheric direct current electric field. Alternate exposure and shielding of the sensor electrodes generates a to-and-fro motion of charge between the ground and the sensor plates through a high resistance resistor. This moving charge promotes an alternating current, which appears as an alternating current voltage across the sensor resistor. The magnitude of this alternating current and the corresponding alternating current voltage is proportional to the strength of the direct current atmospheric electric field. This voltage is amplified and fed into an analog-to-digital converter. The data is stored in a computer with a sampling rate of 1 datum/s. To maintain time synchronization, the internal clock of the computer is synchronized with a GPS receiver. The maximum electric field that can be measured by such an EFM is $\pm 20 \mathrm{kVm}^{-1}$. However, after the correct calibration and scaling under fair weather conditions, a scaling factor of 0.3 was determined, which restricted the maximum field variation to $\mathrm{ca} . \pm 6 \mathrm{kVm}^{-1}$ at a height of $15 \mathrm{~m}$ from the ground, where the EFM was installed. The EFM detected electric field variations due to cloud activity within a radius of $30 \mathrm{~km}$.

\section{Analysis of data and observational results}

The diurnal variation of the VEF is continuously affected by the presence of clouds, thunderstorms (both local and global), precipitation, geomagnetic storms, and aerosol concentrations, among other factors [Rycroft et al. 2000, Harrison and Aplin 2002, Bennett and Harrison 2007]. Thus, it is necessary to distinguish between any seismic effects on the VEF measurements and various local or global perturbations. Our geographical location is at the juncture point of three tectonic plates: the Eurasian, Indian and Australian plates (Figure 1). Therefore, it is a strategically significant place to perform a statistical study on precursory variations in VEF measurements before major local earthquakes. Three years of VEF data from July 2009 to July 2012 were selected for the present analysis. First of all, the fair-weather days were selected from among the whole range of data. We defined fair-weather conditions as a maximum wind

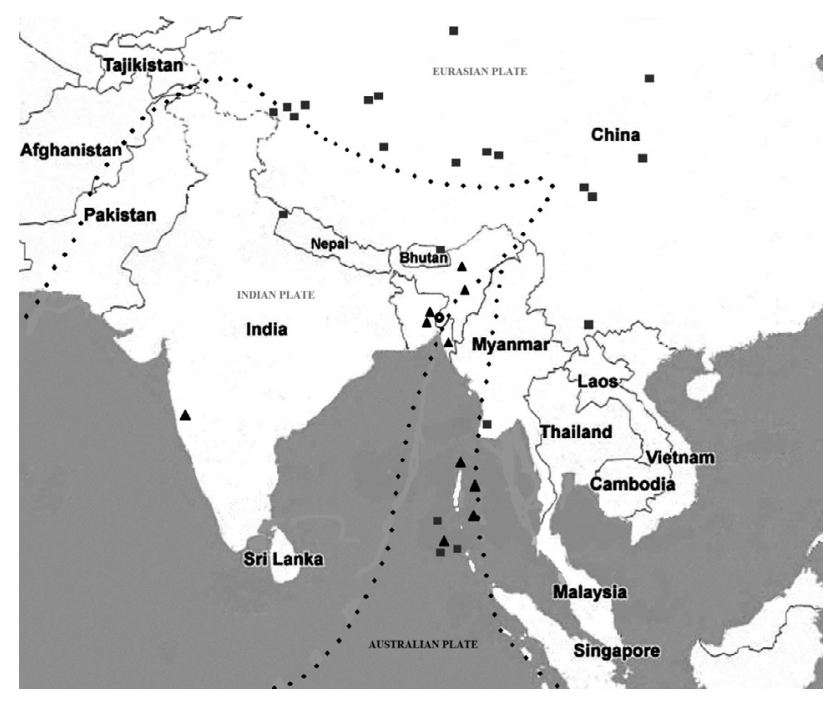

Figure 1. Map of the geographical positions of all of the 10 earthquakes for which the precursor variations were observed (triangles) along with location of the VEF instrument (open circle). The remaining 22 of the 32 earthquakes, where precursors were not observed, are also shown (rectangles). Dashed lines demonstrate the limit of Eurasian, Indian and Australian plates. 


\begin{tabular}{lcccccccc}
\hline EQ Dates & $\begin{array}{c}\text { Magnitude } \\
(\mathbf{M})\end{array}$ & $\begin{array}{c}\text { Depth } \\
(\mathbf{D})\end{array}$ & $\mathbf{M} / \mathbf{D}$ & $\begin{array}{c}\Delta \mathbf{t}^{\star} \\
(\mathrm{hr}: \mathrm{min}: \mathrm{sec})\end{array}$ & $\begin{array}{c}\text { VEF Depth } \\
(\mathrm{kV} / \mathrm{m})\end{array}$ & $\begin{array}{c}\text { VEF Duration } \\
(\mathbf{h r}: \text { min:sec })\end{array}$ & $\begin{array}{c}\text { Dist. from } \\
\text { Epicenter }(\mathbf{k m})\end{array}$ & $\begin{array}{c}\text { Preparation } \\
\text { Zone }(\mathrm{km})\end{array}$ \\
\hline 26.07 .2009 & 5.2 & 10 & 0.52 & $08: 20: 59$ & 0.714 & $01: 01: 34$ & 1460 & 172 \\
12.12 .2009 & 5.0 & 10 & 0.50 & $05: 15: 26$ & 0.548 & $00: 53: 32$ & 1924 & 141 \\
13.12 .2009 & 5.1 & 10 & 0.51 & $11: 15: 47$ & 0.633 & $00: 51: 36$ & 140 & 156 \\
01.05 .2010 & 4.6 & 12 & 0.38 & $10: 06: 40$ & 0.834 & $00: 53: 33$ & 1110 & 95 \\
12.06 .2010 & 7.8 & 10 & 0.78 & $14: 05: 08$ & 1.385 & $00: 40: 42$ & 1763 & 2260 \\
10.09 .2010 & 4.8 & 15 & 0.32 & $11: 22: 56$ & 0.804 & $01: 10: 22$ & 133 & 116 \\
12.12 .2010 & 4.8 & 15 & 0.32 & $06: 05: 27$ & 0.457 & $01: 04: 50$ & 269 & 116 \\
12.02 .2011 & 4.0 & 10 & 0.40 & $07: 42: 30$ & 0.515 & $00: 54: 40$ & 70 & 53 \\
24.04 .2012 & 5.5 & 10 & 0.55 & $12: 16: 08$ & 0.684 & $00: 59: 36$ & 1580 & 232 \\
11.05 .2012 & 5.4 & 20 & 0.27 & $12: 39: 22$ & 0.562 & $01: 17: 35$ & 370 & 210 \\
\hline
\end{tabular}

Table 1. Details of the 10 earthquake days where the precursors were observed. $\Delta \mathrm{t}^{\star}$, time difference between occurrence of bay-like variation in the VEF and the earthquake.

\begin{tabular}{|c|c|c|c|c|c|c|c|c|}
\hline Date & $\begin{array}{l}\text { EQ Time } \\
\text { (IST) }\end{array}$ & Lat & Long & $\begin{array}{l}\text { Depth } \\
\text { (D) }\end{array}$ & $\begin{array}{l}\text { Magnitude } \\
\text { (M) }\end{array}$ & M/D & $\begin{array}{c}\text { Dist. from } \\
\text { Epicenter }(\mathbf{k m})\end{array}$ & $\begin{array}{c}\text { Preparation } \\
\text { Zone }(\mathbf{k m})\end{array}$ \\
\hline $2012-03-27$ & $03: 24: 54.38$ & 33.284 & 95.605 & 11.4 & 4.1 & 0.36 & 1167 & 58 \\
\hline 2012-03-04 & $22: 41: 45.44$ & 30.167 & 101.767 & 10.0 & 4.3 & 0.43 & 1217 & 71 \\
\hline $2012-02-20$ & $19: 48: 03.82$ & 35.840 & 79.835 & 10.0 & 5.0 & 0.50 & 1757 & 141 \\
\hline 2012-01-01 & $10: 49: 34.93$ & 10.632 & 91.737 & 10.0 & 4.6 & 0.46 & 1431 & 95 \\
\hline $2011-12-14$ & 11:09:25.15 & 39.463 & 94.384 & 10.0 & 4.7 & 0.47 & 1798 & 105 \\
\hline $2011-11-30$ & $01: 12: 34.43$ & 7.802 & 93.858 & 17.0 & 5.6 & 0.33 & 1766 & 256 \\
\hline 2011-11-13 & $11: 59: 11.66$ & 36.045 & 81.066 & 10.0 & 4.1 & 0.41 & 1703 & 58 \\
\hline 2011-09-24 & 09:38:58.84 & 36.377 & 82.526 & 10.0 & 4.3 & 0.43 & 1650 & 71 \\
\hline 2011-08-01 & $01: 10: 53.48$ & 33.739 & 87.574 & 13.6 & 5.1 & 0.37 & 1192 & 156 \\
\hline 2011-01-23 & $21: 16: 19.83$ & 23.034 & 101.689 & 10.0 & 4.2 & 0.42 & 1066 & 64 \\
\hline $2010-11-28$ & $10: 03: 47.10$ & 7.588 & 91.875 & 15.8 & 4.2 & 0.26 & 1770 & 64 \\
\hline 2010-11-06 & $07: 42: 43.64$ & 36.636 & 87.506 & 10.0 & 5.2 & 0.52 & 1503 & 172 \\
\hline 2010-09-08 & $07: 28: 10.63$ & 33.315 & 96.365 & 10.0 & 4.2 & 0.42 & 1199 & 64 \\
\hline $2010-07-25$ & $14: 27: 03.95$ & 16.345 & 94.611 & 10.0 & 4.6 & 0.46 & 869 & 95 \\
\hline $2010-06-22$ & $04: 44: 10.84$ & 29.872 & 80.428 & 16.3 & 5.2 & 0.32 & 1285 & 172 \\
\hline $2010-04-27$ & $01: 52: 27.72$ & 30.432 & 101.424 & 10.0 & 5.1 & 0.51 & 1267 & 156 \\
\hline 2010-03-10 & 20:02:21.77 & 36.426 & 86.966 & 10.0 & 5.1 & 0.51 & 1493 & 156 \\
\hline 2010-03-03 & $20: 05: 3.33$ & 32.821 & 105.211 & 13.1 & 4.3 & 0.33 & 1713 & 71 \\
\hline $2009-12-18$ & $10: 49: 30.08$ & 32.641 & 92.841 & 10.0 & 4.6 & 0.46 & 1027 & 95 \\
\hline $2009-12-01$ & $16: 53: 28.43$ & 27.272 & 91.455 & 10.0 & 4.2 & 0.42 & 419 & 64 \\
\hline 2009-11-20 & $04: 24: 19.36$ & 37.157 & 101.978 & 10.0 & 4.2 & 0.42 & 1829 & 64 \\
\hline 2009-08-09 & 09:32:07.30 & 35.578 & 81.647 & 10.0 & 5.1 & 0.51 & 1630 & 156 \\
\hline
\end{tabular}

Table 2. Details of the 22 earthquake days where no precursors were observed despite the fair-weather conditions.

speed of $4 \mathrm{~m} / \mathrm{s}$, less than 3 octa cloud cover, and no cumulonimbus clouds visible in the sky from the observation site [Latha 2003], and also with no precipitation. The confirmation of fair-weather conditions was also verified according to the data from an automatic weather station (set-up at our receiver position), and from lightning im- aging satellites and meteorological and oceanographic satellites for this region. However, due to the adverse geographical location of our receiver, which is located at the foot hills of the Himalayas and also in one of the regions with the highest rainfall in the world (Cherrapunji, with an average yearly rainfall of ca. 12,000 mm, 
is within $350 \mathrm{~km}$ of the observational site), ideally clear meteorological days were rare. Next, we looked for local earthquakes that occurred in the vicinity of about $2000 \mathrm{~km}$ from the receiver position, but only during these meteorologically fair days. A total of 32 such earthquakes were reported over the 3 years of the observational period. Among these, there were only 10 cases of VEF variations in the form of bay-like depressions in the VEF magnitudes that were observed as precursors to these earthquakes (as listed in Table 1). Figure 1 shows the geographical positions of these 10 earthquakes for which the precursor variations were observed (Figure 1, triangles), along with the location of the VEF receiver (Figure 1, open circle). The remaining 22 of the 32 earthquakes, where precursors were not observed, are indicated with gray rectangles in Figure 1, and the full details are provided in Table 2 . In the present analysis, the earthquakes with earthquake magnitude to depth ratios $>0.25$ were only considered. The reason behind the selecting of this ratio was to introduce both the earthquake magnitude as well as depth into the analysis. Also, if two successive earthquakes occurred within an interval of $24 \mathrm{~h}$, they were considered as a single event. Only the negative anomalies in VEF that preceded an earthquake by no more than 24 $\mathrm{h}$ were considered in the statistical analysis.

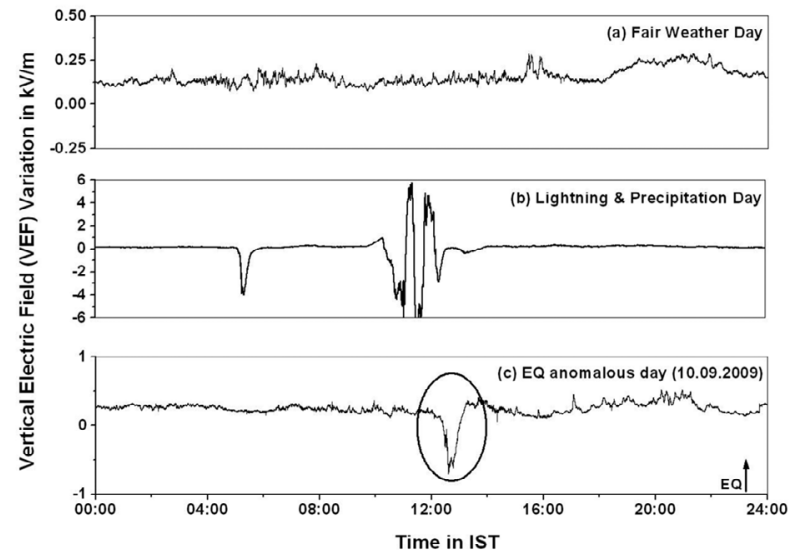

Figure 2. Typical diurnal variations in the VEF for a meteorologically fair-weather day (a), a day with local lightning and precipitation (b), and a day with fair weather and an anomalous VEF variation that preceded an earthquake (c). Arrow, time of the main strike of the earthquake.

Figure 2 shows the typical diurnal variation in the VEF for a meteorologically fair weather day (Figure 2a), a day with local lightning and precipitation (Figure 2b), and a day with fair weather and an anomalous VEF variation that preceded an earthquake (Figure $2 \mathrm{c}$ ). In Figure $2 \mathrm{c}$, the bay-like variation is highlighted by the circle, and the time of the earthquake is indicated by an upward arrow. We also checked the selected 10 days for any solar and geomagnetic storm events. Nine of

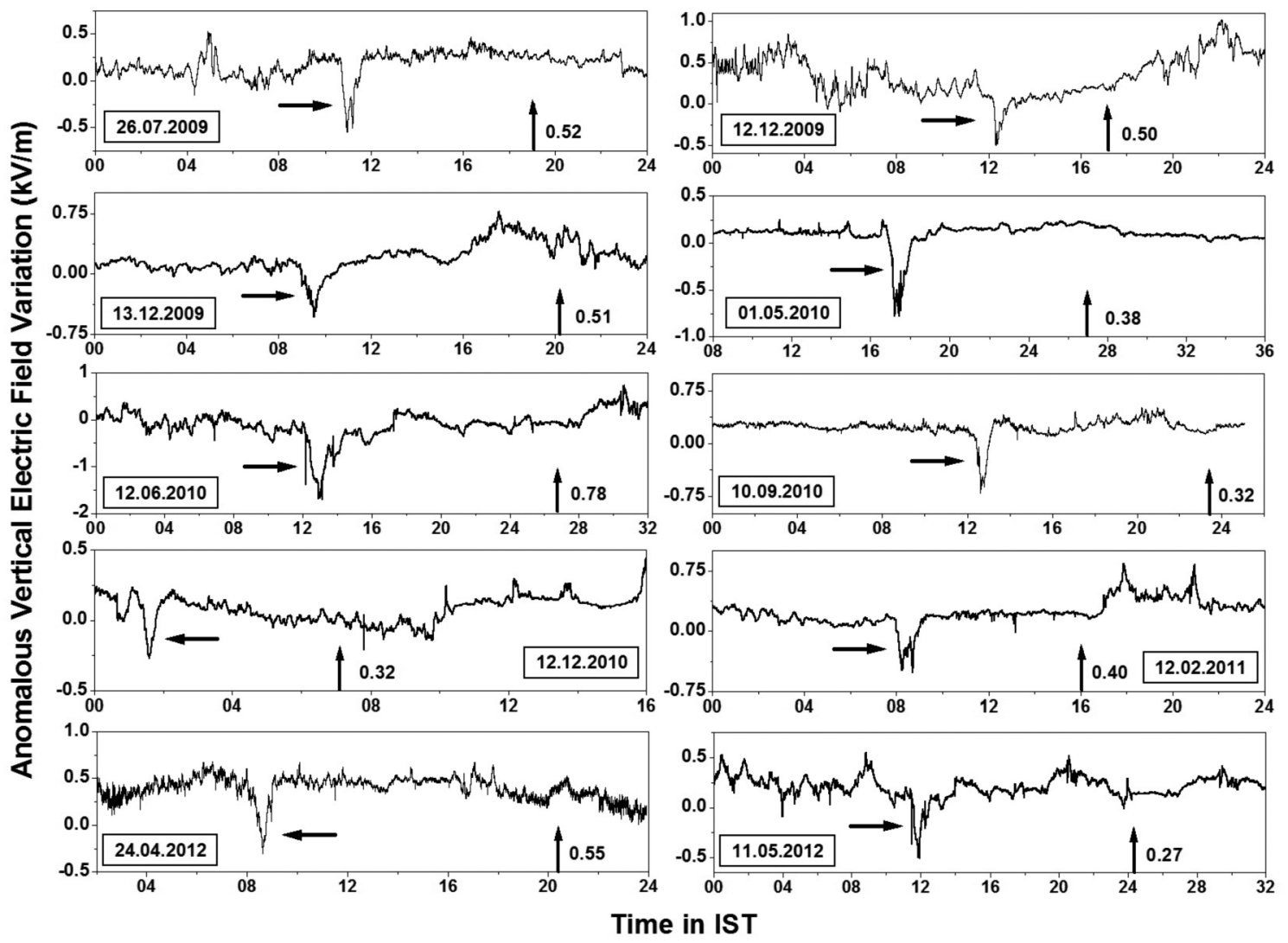

Figure 3. Diurnal variations in the VEF along with the earthquake for the 10 cases where a precursor was observed. Arrow to right/left, anomalous VEF variations; arrow up, time of strike of the earthquake plus ratio of earthquake magnitude to depth. 


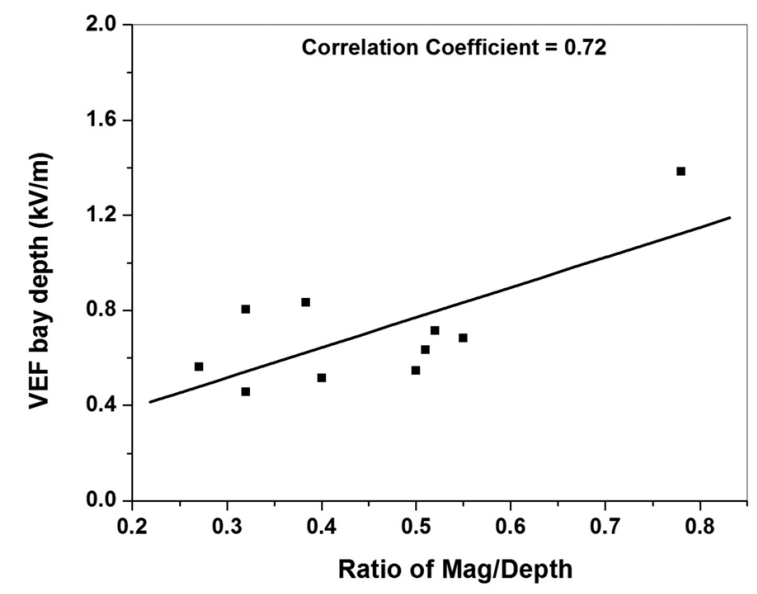

Figure 4. Correlation plot between the ratio of magnitude to depth and the VEF bay depth.

these 10 days were very quiet days, while one, namely April 24, 2012, was associated with a minor geomagnetic storm of $\mathrm{K}_{\mathrm{p}}=5$. Figure 3 shows all of the 10 days of the bay-like VEF variations, along with the earthquake strike times. The anomalous bay-like variations in the VEF are shown by sidewise arrows, while the times of the associated earthquakes and the corresponding ratios of the magnitude to the depth are shown by upward arrows (Figure 3).

To determine if there was any dependency of earthquake class on the VEF variations, we selected the ratio of the magnitude to the depth of the epicenter of each earthquake as a parameter to define all 10 of the earthquakes. There was a positive correlation coefficient of 0.72 , with the associated $95 \%$ confidence interval from 0.16 to 0.93 (www.psyctc.org/stats/R/CI_
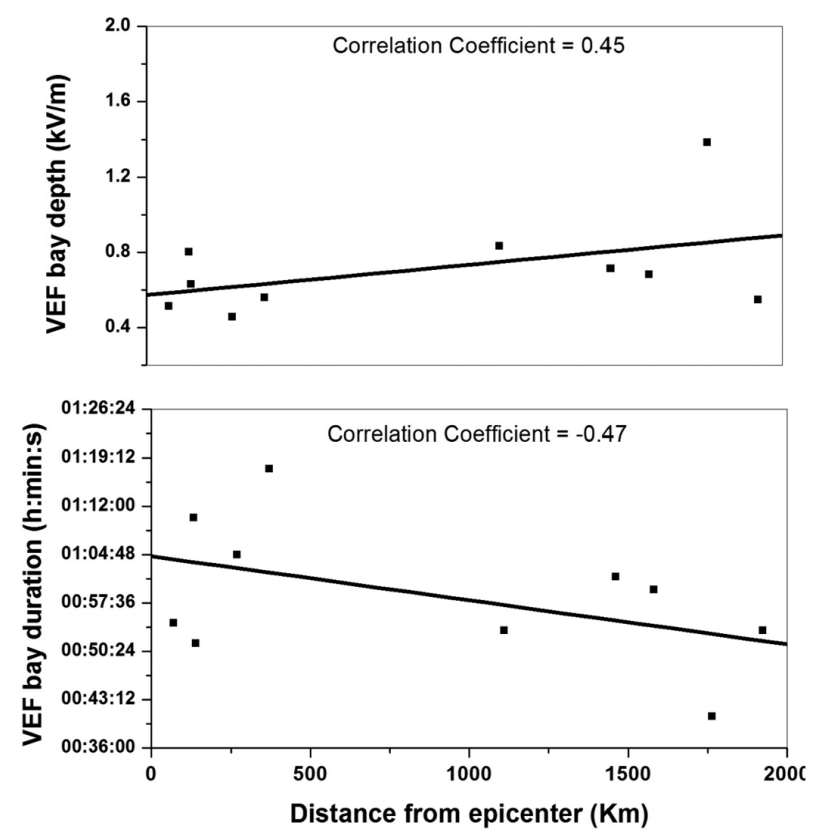

Figure 6. Correlation plot between the distance of the earthquake epicenter to the receiver and the VEF bay depth (top) and VEF bay duration (bottom).

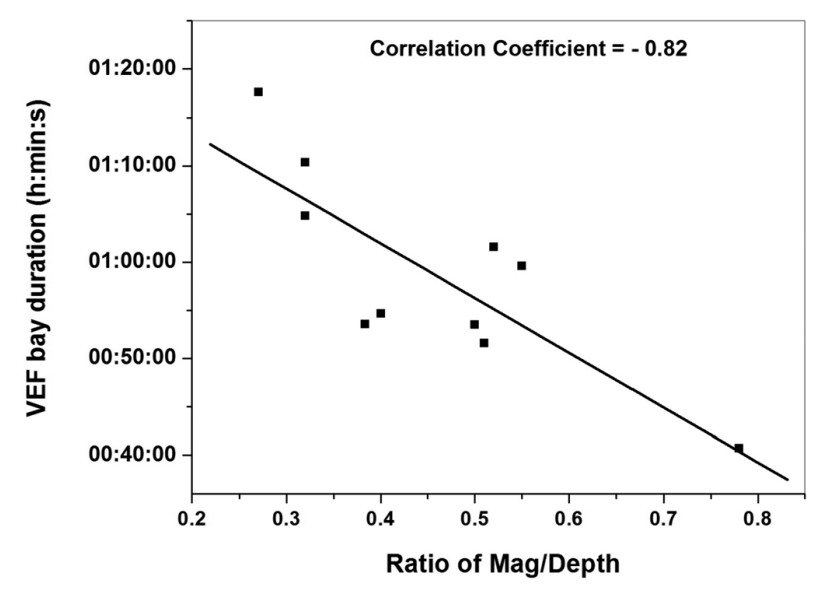

Figure 5. Correlation plot between the ratio of magnitude by depth and the VEF bay duration.

correln1.html), for the plot between the ratio of the magnitude to the depth and the VEF bay depth, as shown in Figure 4. Figure 5 shows a further plot between the ratio of the magnitude to the depth and the VEF bay duration, which shows a negative correlation coefficient of -0.82 , with a $95 \%$ confidence interval from -0.96 to -0.39 . We then determined if there was any dependence between the distance of the earthquake epicenter to the observation point and the VEF bay depth, and also the VEF bay duration (Figure 6). The computed correlation coefficients were 0.45 and 0.47 , with $95 \%$ confidence intervals from -0.25 to 0.84 and from -0.85 to 0.23 , respectively. This indicates that there might be moderate dependence of the bay depth and the bay duration on the distance of the epicenters. Figure 7 shows the time difference $(\Delta t)$ between the oc-
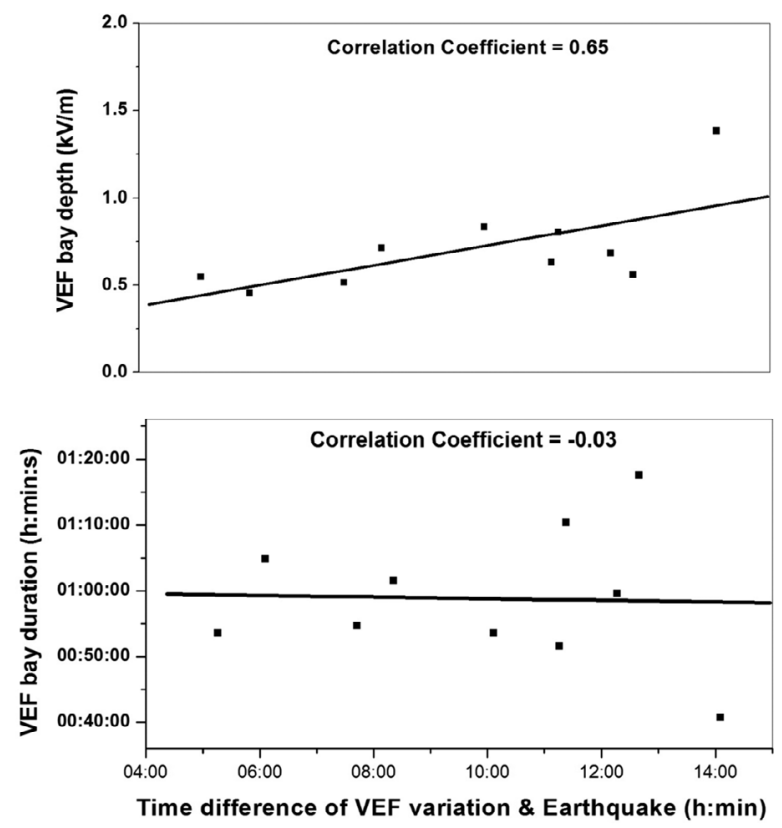

Figure 7. Correlation plot between the time duration of the observed precursor of the earthquake and the VEF bay depth (top) and VEF bay duration (bottom). 


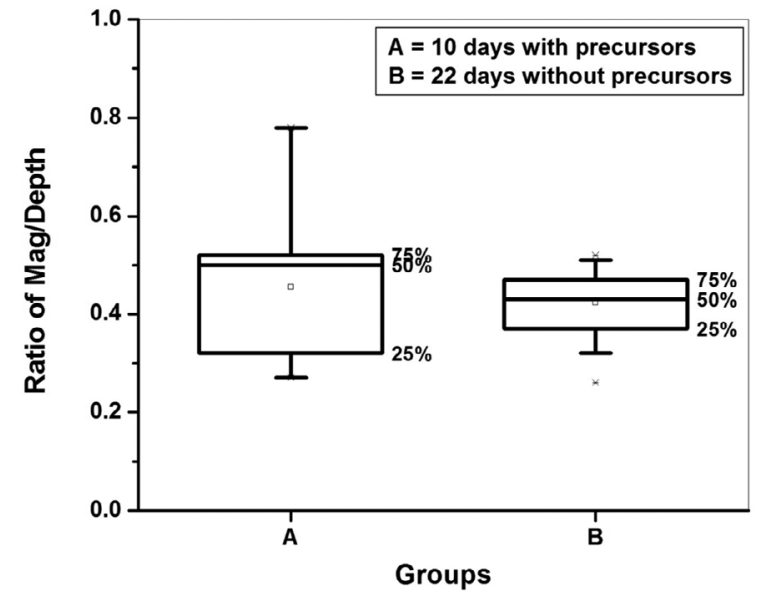

Figure 8. Box plot comparing the 10 days with precursors observed (group A) and the 22 days without precursors observed (group B) with the ratio of earthquake magnitude to depth.

currence of the bay-like variations in the VEF and the earthquakes, according to the bay depth and bay duration. For the VEF bay depth, there was a positive correlation of 0.65 , with a $95 \%$ confidence interval from 0.03 to 0.91 , although the VEF bay duration plot was a scattered graph which showed very low correlation (Figure 7). A box plot (Figure 8) was plotted between the 10 cases where the precursors were observed (Group A) and the 22 cases (i.e., of the total of 32 fairweather days with earthquakes) without precursors (Group B), to compare these two groups. Here, the distribution was well scattered for Group A, with a mean ratio of 0.5 and a maximum ratio of 0.78 for the earthquake magnitude to depth ratio. For Group B the distribution was relatively suppressed for the earthquake magnitude to depth ratio, with a mean of 0.43 and a maximum of 0.5 , from which it is hard to quantify a specific range for earthquake precursors.

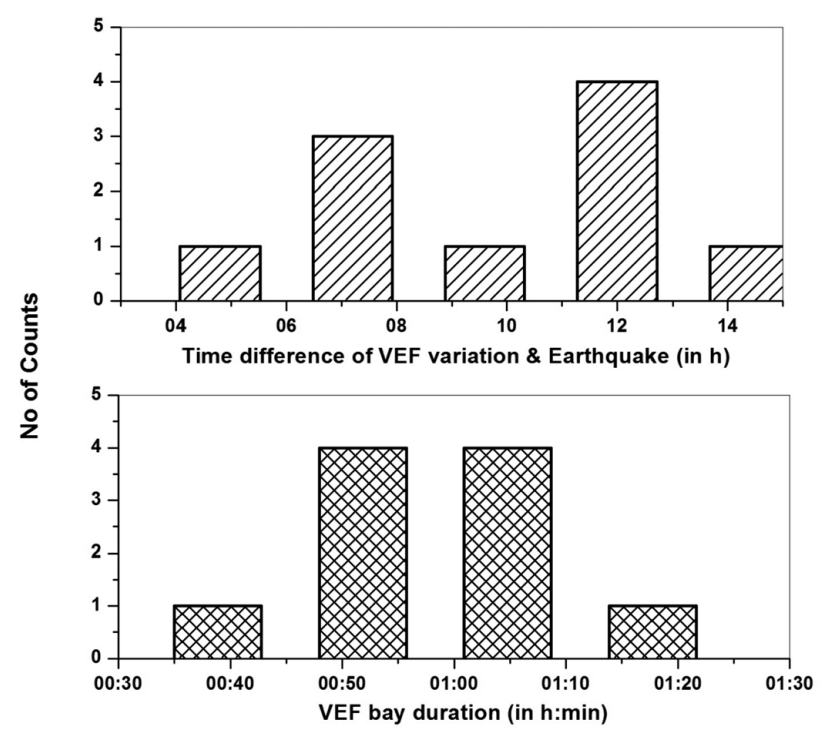

Figure 9. Histograms showing time difference of VEF variation (top) and earthquake and VEF bay duration (bottom).
From the investigations of the ten earthquakes, we found the mean VEF bay-depth variation to be ca. 500 $\mathrm{Vm}^{-1}$ to $800 \mathrm{Vm}^{-1}$, with a maximum variation of around $1385 \mathrm{Vm}^{-1}$. Here, the mean VEF bay duration was within the range of $50 \mathrm{~min}$ to $70 \mathrm{~min}$, with the maximum variation as 77 minutes. The most probable VEF precursors were seen $7 \mathrm{~h}$ to $12 \mathrm{~h}$ before an impending earthquake, whereas the maximum variation was ca. $14 \mathrm{~h}$ and $5 \mathrm{~min}$ (Figure 9). One of the most interesting things about all 10 of these earthquakes was that all of them were shallow; i.e., within $10 \mathrm{~km}$ to $20 \mathrm{~km}$ in depth only. From a total of 32 earthquakes reported during the time period of our data analysis, only 10 showed VEF variations, indicating a $31 \%$ probability of VEF earthquake precursors from our data, considering within $24 \mathrm{~h}$ before an impending earthquake, and only during the meteorologically clear days.

\section{Discussion}

The atmospheric VEF near the Earth surface exists under all weather conditions. Under fair-weather conditions, these VEFs arise through the GEC, due to thunderstorms occurring in meteorologically disturbed regions around the globe. In the fair weather regions, the VEF is around $100 \mathrm{Vm}^{-1}$, and it shows an identifiable global diurnal variation, known as the Carnegie variation. This is named after the sailing vessel on which the original marine measurements were performed and named [Parkinson and Torreson 1931, Guha et al. 2010]. Generally for atmospheric electricity, fair-weather electric fields are considered as negative [Pawar and Kamra 2002] in a spherical polar coordinate system, although in our analysis here we took the fairweather electric fields to be positive, as per convention of fair-weather atmospheric electricity.

Among all of the scientific reports on variations in atmospheric electric field before earthquakes, Pierce [1976] made the first observations of a 30\% decrease in the electric field from its ambient value. Thereafter, several reports across the scientific literature were presented that showed quasistatic anomalous electric field variations before earthquakes [Kondo 1968, Rulenko et al. 1992, Hao et al. 2000, Smirnov 2005]. The exact variation is something like a negative bay-like anomaly in the VEF, with a sharp leading front and subsequent smooth recovery to the background level over a period of time, which has been observed as a few hours before several earthquakes reported from Kamchatka (Russia), Japan, Taiwan and China [Mikhailov et al. 2003, Mikhailov et al. 2006, Smirnov 2001, Kamogawa et al. 2004, Zhang-Hui et al. 2011].

Smirnov [2008] carried out a statistical study at Kamchatka from 1997 to 2002 over 103 cases of bay-like 
depressions in the strength of the near Earth atmospheric electric field $\left(\mathrm{E}_{\mathrm{z}}\right)$ and found the most probable bay duration to be $40 \mathrm{~min}$ to $60 \mathrm{~min}$. The most probable negative variations in $\mathrm{E}_{\mathrm{z}}$ are around $106 \mathrm{Vm}^{-1}$ to 300 $\mathrm{Vm}^{-1}$. No dependence of these values on the earthquake class or the distance to the epicenter was found. The probability of earthquake forecasting over a $24 \mathrm{~h}$ period before an earthquake based on the $\mathrm{E}_{\mathrm{z}}$ anomaly has been shown to be around $36 \%$. Another statistical study was reported from Lisbon (Portugal) for the period from 1955 to 1991, which examined the influence of seismic activity on the VEF, to define an exploratory method that involved the selection of events for which the distance from the atmospheric electrical field sensor to the earthquake epicenter was smaller than the preparation radius of the event [Silva et al. 2012]. In our statistical investigation, for northeast India, we found that the mean VEF bay-depth variations for earthquake precursors to be ca. $500 \mathrm{Vm}^{-1}$ to $800 \mathrm{Vm}^{-1}$, whereas the average VEF bay duration was about 50 min to 70 minutes. The most probable VEF precursors were observed $7 \mathrm{~h}$ to $12 \mathrm{~h}$ prior to earthquakes.

Processes like cosmic rays, solar radiation, lightning discharge, natural ground radioactivity and aerosol concentration all contribute to the air ionization and consequent latent heat release due to water vapor condensation on the newly formed ions, and hence the resulting changes in the VEF [Pudovkin and Raspopov 1992, Svensmark and Friis-Christensen 1997, Rulenko 2000, Freund et al. 2009]. Thus it is necessary to be sure enough to identify the precursor effects on the VEF from among all of these effects. Accordingly, at our location, the fair-weather VEF graph looks something like that shown in the top panel of Figure 2, which shows a quiet background level of about $120 \mathrm{Vm}^{-1}$ to $170 \mathrm{Vm}^{-1}$ at local morning and noon hours, with a further increase at the evening up to $250 \mathrm{Vm}^{-1}$ to $300 \mathrm{Vm}^{-}$ ${ }^{1}$, the dynamic range of which is consistent with other land observations [Mikhailov et al. 2002, 2003, Smirnov 2005]. When a cloud passes over our receiver and with no precipitation, the VEF reading is about $4000 \mathrm{Vm}^{-1}$ to $4500 \mathrm{Vm}^{-1}$, while with lightning and precipitation the VEF shows relatively chaotic positive and negative deviations from the mean diurnal behavior of about 6000 $\mathrm{Vm}^{-1}$. In contrast, the anomalous variations of VEF for these earthquake precursors during fair-weather days is about $500 \mathrm{Vm}^{-1}$ to $800 \mathrm{Vm}^{-1}$. Thus the observed VEF variation is well distinguishable from local cloud passing over the sensor, and from the local lightning and thunderstorm activity. As a result, in the total duration of our analysis, we found a total of 32 cases of earthquakes during fair-weather days and among these only 10 showed VEF variations in the form of bay-like de- pressions in the VEF magnitude, which were seen as a precursory for an earthquake.

A positive dependency was found between earthquake class and VEF bay depth, which is shown in Figure 4. This signifies that with larger earthquake magnitudes (since the depths were almost equal in our observations; see Table 1) the VEF bay depth will be more. Whereas a negative correlation was observed between the earthquake class and the VEF bay duration, which highlights that as the earthquake magnitude decreases, the duration of the VEF bay variation increases, and vice versa. Our observations here contrast with those of Smirnov [2008], who monitored the Kamchatka seismicity, where there was no dependence of bay duration and bay strength on earthquake class or distance from the epicenter. However, we also observed a low dependency between VEF bay duration and depth with the distance of the earthquake epicenter from the observation point. The probable cause might be due to some difference between the seismicity of Kamchatka and northeast India, which is located at the juncture of three tectonic plates: namely, the Indian, Eurasian and Australian (Figure 1).

Among the various models proposed in the literature, radon emanation is viewed as a significant cause of such VEF variations [Smirnov 2008]. Radon is a product of uranium decay series that has a short half-life of 3.8 days, and due to this, radon shows poor intrinsic mobility [Singh et al. 2010]. As a consequence of radon emanation, long-living ion complexes of opposite signs are formed in the near ground layer of the atmosphere. Ions of different signs have different mobilities; generally the mobility of the negative ions is 1.3-1.4-fold more than for positive ones. Under the actions of the natural atmospheric electric field, the positive ions would tend to move to the surface of the Earth, where they would recombine, but because of their low mobility, after some time, a spatial layer of positive ions will be formed at the surface, whereas the negative ions will move vertically upwards. In such a way, at the near ground, an 'electrode layer' can be formed, along with the local electric field, which diminishes the natural atmospheric electric field, which is known as the 'electrode effect' [Hoppel 1967, Pulinets and Boyarchuk 2004]. It is thus expected that the changes in surface radon emission would modify the surface atmospheric electricity conditions and potentially lower the ionospheric properties, via the weak fairweather conduction current that carries the negative charge upwards throughout the troposphere and stratosphere [Harrison et al. 2010]. Moreover, more recently, Freund et al. [2009] showed that the charge generated in stressed rock can travel over distances of several kilometers, to reach the surface and to enhance the air ionization, which consequently induces atmospheric electrical 
perturbations. However, air ionization by increased radon release before earthquakes might be only a small part of the total ionization balance, and the identification of the atmospheric processes that are initiated by earthquake preparation processes is part of short-term earthquake prediction [Pulinets and Ouzounov 2011]. The release of radon into the atmosphere is also thought to be closely related to the state of deformation processes in the surface layers of the Earth during the earthquake preparation phase [Rulenko et al. 1992, Rulenko 2000]. Among the few such models proposed, Morgounov and Maltsev [2003] suggested a model that generates a quasistatic electric field in the atmosphere by considering the formation of polarization charges on the walls of rock fractures. Whereas Alekseev and Aksenov [2003] pointed out that electrical conductivity between the air and the Earth depends on the conductivity of the fluids that fill the rock pores and fractures, which ultimately have effects on the atmospheric electric field. More importantly, at the lower latitude regions, under relatively geophysical conditions, the equatorial anomaly or Appleton anomaly formation occurs as a regular daytime phenomena, and might lead to generation of an anomalous zonal electric field [Pulinets 2012], thus separating our location from the higher latitude regions. This might be a reason as to why in spite having some fair-weather days, we did not observed any precursors from the China region, which is above $30^{\circ}$ North; i.e. outside the equatorial anomaly region.

Sobolev [1993] stated that these VEF variations are short-term predictors and cannot be used over the long term. So generally in this type of VEF, the variation does not follow the empirical formulae of $10^{0.43 \mathrm{M}}$ for earthquake preparation zones. This has also been observed in our records as well. From Table 1, it can be seen that 8 of the 10 earthquakes showed precursor effects even outside the earthquake preparation zone. Morgounov [2004] provided an explanation of this by means of nonuniformity of the stress and strain processes in the Earth crust before impending earthquakes. Another point to be noted from Figure 1 is that the positions of almost all of the 31 of the 32 earthquakes under study, both with and without precursors, occurred more or less near the tectonic plate boundaries, although there was an exception in one case where the precursor was being observed, and its position was situated far to the west, near Mumbai, which is good distant from any tectonic plates (Figure 1). However the probable cause of this is still a matter of further investigation. These pre-seismic variations on the atmospheric electric field could be due to a surface ionospheric coupling mechanism [Kamogawa et al. 2004]. Kamogawa [2006] and Hayakawa [2006] sum- marized three possible coupling mechanisms. They highlighted that the gases released from the ground during plate motion before major earthquake shocks modulate the properties of the entire atmosphere. Secondly, ground motions might also excite atmospheric gravity waves that propagate upwards. Lastly, electromagnetic radiation produced by processes acting in the ground before earthquakes could also initiate ionospheric effects. Liperovsky et al. [2008] highlighted that different physical mechanisms acting together are necessary to explain the same precursor event as well. But Pulinets and Ouzounov [2011] raised questions against this, and they introduced a model known as the Lithosphere-Atmosphere-Ionosphere Coupling (LAIC) model. This model discusses a mechanism that exists between different layers of the atmosphere, which might explain the linkage of events occurring simultaneously before an earthquake, between the ground surface, the atmosphere and the ionosphere.

So, from the above discussions, it is perhaps reasonable to suggest that radon emanation might not be the sole source of VEF variations before earthquakes. Although from Figure 8, for the ratio of earthquake magnitude to depth above 0.5 , there is a possibility of getting a precursor; however, this is still hard to confirm, and it might not always be a governing factor. A more complex mechanism deep inside the Earth crust could be responsible for all of these variations in the VEF, and this link might map its effects on the entire atmosphere before an impending earthquake. Nevertheless, the main objective of this study was only to demonstrate the VEFs from the earthquake prone zone of northeast India, and discuss the probable causes of these perturbations. As we do not have any radon-monitoring devices in the vicinity of the receiver to potentially correlate this with our observed results, we cannot at present verify this hypothesis. Furthermore, from Figure 3, it appears that $90 \%$ (i.e., 9 out of these 10 earthquakes) of the precursors appear before 14:00 IST and 70\% (7 out of 10) earthquakes strike in between 16:00 and 24:00 IST. This might not be mere coincidence, as Pulinets et al. [1998] showed dependence of the local time on the seismic ionospheric variations. However, at this stage our main objective was the ratio of earthquake magnitude to the depth, so these further aspects are beyond the scope of the present study.

\section{Concluding remarks}

The present study is the first preliminary statistical observation made from a region of the globe where no similar previous studies have been made. From the present analysis, good correlation was found between the VEF bay depth and bay duration with the ratio of the 
earthquake magnitude to the depth, while low dependence was found for both the distance of the earthquake epicenter to the observation point, and the time of the observed precursor of the earthquake, for both the VEF bay depth and VEF bay duration. Various sources have indicated that these changes in ionization are due to radon emanation or might be due to seismo-ionosphere coupling; we might have observed the decrease of VEF before earthquakes but no consensus has been reached. This makes the subject very interesting, but nevertheless complex, which the need for extensive studies here. We believe that longer duration VEF data along with continuous radon monitoring have good spatial distributions in strategic locations, and further investigations carried out in a coherent manner are required to provide more convincing data with regard to this potential precursory phenomenon of earthquakes.

Acknowledgements. The authors are thankful to Department of Science and Technology, Government of India, for providing financial support to conduct the research through Department of Physics, Tripura University, Suryamaninagar, India, under the INSPIRE Fellowship Programme.

\section{References}

Adlerman, E.J., and E.R. Williams (1996). Seasonal variation of the global electrical circuit, J. Geophys. Res., 101, 679-688.

Alekseev, A.S., and V.V. Aksenov (2003). On an electric field in an earthquake epicenter, Dokl. Akad. Nauk., 392, 106-110.

Bennett, A.J., and R.G. Harrison (2007). Atmospheric electricity in different weather conditions, Weather, 62, 277-283.

Bering, E.A. (1995). The global circuit: global thermometer, weather by product or climate modulator?, Rev. Geophys., 33, 845-862.

Freund, F.T., I.G. Kulahci, G. Cyr, J. Ling, M. Winnick, J. Tregloan-Reed and M.M. Freund (2009). Air ionization at rock surfaces and pre-earthquake signals, J. Atmos. Sol.-Terr. Phys., 71, 1824-1834.

Fullekrug, M. (2004). The contribution of intense lightning discharges to the global atmospheric electric circuit during April 1998, J. Atmos. Sol.-Terr. Phys., 66, 1115-1119.

Guha, A., B.K. De, S. Gurubaran, S.S. De and K. Jeeva (2010). First results of fair-weather atmospheric electricity measurements in northeast India, J. Earth Syst. Sci., 119, 221-228.

Hao, J., T., Tang and D. Li (2000). Progress in the research of atmospheric electric field anomaly as an index for short-impending prediction of earthquakes, J. Earthq. Pred. Res., 8, 241-255.

Harrison, R.G., and K.L. Aplin (2002). Mid-nineteenth century smoke concentrations near London, Atmos. Environ., 36, 4037-4043.

Harrison, R.G., K.L. Aplin and M.J. Rycroft (2010). Atmospheric electricity coupling between earthquake regions and the ionosphere, J. Atmos. Sol.-Terr. Phys., 72, 376-381.

Hayakawa, M. (2006). Electromagnetic phenomena associated with earthquakes, IEEJ. Trans. FM., 126, 211-214.

Hoppel, W.A. (1967). Theory of electrode effect, J. Atmos. Terr. Phys., 29, 709-721.

Kamogawa, M., J.Y. Liu, H. Fujiwara, Y.J. Chuo, Y.B. Tsai, K. Hattori, T. Nagao, S. Uyeda and Y.H. Ohtsuki (2004). Atmospheric field variations before the March 31, 2002 M 6.8 earthquake in Taiwan, TAO, 15, 397-412.

Kamogawa, M. (2006). Preseismic lithosphere-atmosphere-ionosphere coupling, EOS Trans., 87, 417-424.

Kondo, G. (1968). The variation of the atmospheric electric field at the time of earthquake, Kakioka Magn. Obs. Mem., 13, 11-23.

Latha, R. (2003). Diurnal variation of surface electric field at a tropical station in different seasons: a study of plausible influences, Earth Planets Space, 55, 677-685.

Liperovsky, V.A., O.A. Pokhotelov, C.V. Meister and E.V. Liperovskaya (2008). Physical models of coupling in the lithosphere-atmosphere-ionosphere system before earthquakes, Geomagn. Aeron., 48, 795-806.

Litta, A.J., and U.C. Mohanty (2008). Simulation of a severe thunderstorm event during the field experiment of STORM programme 2006, using WRF-NMM model, Curr. Sci., 95, 204-215.

Mikhailov, Yu.M., G.A. Mikhailova, O.V. Kapustina, A.X. Depueva, A.V. Buzevich, G.I. Druzhin, S.E. Smirnov and P.P. Firstov (2002). Variations in different atmospheric and ionospheric parameters in the earthquake preparation periods on Kamchatka: preliminary results, Geomagn. Aeron., 42, 769-776.

Mikhailov, Yu.M., G.A. Mikhailova, O.V. Kapustina, A.V. Buzevich and S.E. Smirnov (2003). Variations in the power spectra of the electric field in the near-Earth atmosphere on Kamchatka, Geomagn. Aeron., 43, 395-401.

Mikhailov, Yu.M., G.A. Mikhailova, O.V. Kapustina, A.V. Buzevich and S.E. Smirnov (2004). Power spectrum features of the near-Earth atmospheric electric field in Kamchatka, Annals of Geophysics, 47 (1), 237-245.

Mikhailov, Yu.M., G.A. Mikhailova, O.V. Kapustina, G.I. Druzhin and S.E. Smirnov (2006). Electric and electromagnetic processes in the near earth atmosphere before earthquakes on Kamchatka, Geomagn. Aeron., 46, 796-808. 
Morgounov, V.A., and S.A. Maltsev (2003). Model of the quasistationary lithospheric electric field, In: Proceedings of the $5^{\text {th }}$ Russian Conference on Atmospheric Electricity, Vladimir, Russia, 2, 59-61.

Morgounov, V.A. (2004). Slip weakening, strain and short-term preseismic disturbances, Annals of Geophysics, 47 (1), 133-149.

Parkinson, W.C., and O.W. Torreson (1931). The diurnal variation of the electric potential of the atmosphere over the oceans, Int. Union. Geomagn. Geophys. Bull., 8, 340-345.

Pawar, S.D., and A.K. Kamra (2002). Recovery curves of the surface electric field after lightning discharges occurring between the positive charge pocket and negative charge centre in a thundercloud, Geophys. Res. Lett., 29, 2108-2111.

Pierce, E.T. ( 1976). Atmospheric electricity and earthquake prediction, Geophys. Res. Lett., 3, 185-188.

Price, C. (2002). Lightning and atmospheric electricity, In: T. Nunn (ed), Encyclopedia of global environmental change, Chichester, UK, 502-503.

Pudovkin, M.I., and O.M. Raspopov (1992). The mechanism of solar activity action on the state of the lower atmosphere and meteoparameters, Geomagn. Aeron., 32, 1-9.

Pulinets, S.A., V.A. Alekseev, A.D. Legen'ka and V.V. Khegai (1997). Radon and metallic aerosols emanation before strong earthquakes and their role in atmosphere and ionosphere modification, Adv. Space Res., 20, 2173-2176.

Pulinets, S.A., A.D. Legen'ka and T.I. Zelenova (1998). Local time dependence of seismoionospheric variations in the F-layer Maimum, Geomagn. Aeron., 38, 178-183.

Pulinets, S.A., and K.A. Boyarchuk (2004). Ionospheric precursors of earthquakes, Springer, Berlin, Germany, 315.

Pulinets, S., and D. Ouzounov (2011). Lithosphere-atmosphere-ionosphere coupling (LAIC) model - an unified concept for earthquake precursors validation, J. Asian Earth Sci., 41, 371-382.

Pulinets, S. (2012). Low latitude atmosphere-ionosphere effects initiated by strong earthquakes preparation process, Int. J. Geophysics, vol. 2012, article ID 131842.

Rulenko, O.P., A.V. Ivanov and A.V. Shumeiko (1992). Short-term atmospheric electric precursor of the Kamchatka earthquake of March 6, 1992, Dokl. Akad. Nauk., 326, 980-982.

Rulenko, O.P. (2000). Operative earthquake precursors in electricity of the near-Earth atmosphere, Vulkanol. Seismol., 4, 57-68.

Rycroft, M.J., S. Israelsson and C. Price (2000). The global atmospheric electric circuit, solar activity and climate change, J. Atmos. Sol.-Terr. Phys., 62, 15631576.

Silva, H.G., M.M. Oliveira, C. Serrano, M. Bezzeghoud, A.H. Reis, R.N. Rosa and P.F. Biagi (2012). Influence of seismic activity on the atmospheric electric field in Lisbon (Portugal) from 1955 to 1991, Annals of Geophysics, 55 (1), 193-197.

Singh, S., A. Kumar, B.S. Bajwa, S. Mahajan, V. Kumar and S. Dhar (2010). Radon monitoring in soil gas and groundwater for earthquake prediction studies in northwest Himalayas, India Terr. Atmos. Ocean. Sci., 21, 685-695.

Smirnov, S. (2001). Anomalous Behavior of the Electric Field Strength before Earthquakes Observed at Paratunka Magnetic Observatory in 1997-2000, SolarTerrestrial Coupling and Electromagnetic Precursors of Earthquakes, Petropavlovsk-Kamchatskii, Russia, 48-49.

Smirnov, C.E. (2005). Characteristics of negative anomalies in the quasistatic electric field in the near-Earth atmosphere on Kamchatka, Geomagn. Aeron., 45, 265-269.

Smirnov, S. (2008). Association of the negative anomalies of the quasistatic electric field in atmosphere with Kamchatka seismicity, Nat. Hazards Earth Syst. Sci., 8, 745-749.

Sobolev, G.A. (1993). Fundamentals of earthquake prediction (in Russian), Nauka, Moscow, 313.

Stow, C.D. (1969). Atmospheric electricity, Rep. Prog. Phys., 32, 1-67.

Svensmark, H., and E. Friis-Christensen (1997). Variation of cosmic ray flux and global cloud coverage a missing link in solar-climate relationships, J. Atmos. Sol.-Terr. Phys., 59, 1225-1232.

Zhang-Hui, A.N., D.U. Xue-Bin, F. Ying-Ying, L. Jun, T. Da-Cheng, C. Jun-Ying and X. Tao (2011). A study of the electric field before the Wenchuan 8.0 earthquake of 2008 using both space-based and groundbased observational data with spectral element method simulation, Chinese J. Geophys., 54, 818-827.

\footnotetext{
${ }^{\star}$ Corresponding author: Anirban Guha,

Tripura University, Department of Physics, Suryamaninagar, Agartala, India; email: anirban1001@yahoo.com.

C 2013 by the Istituto Nazionale di Geofisica e Vulcanologia. All rights reserved.
} 